\title{
Can Scientific and Technological Talent Aggregation Accelerate Economic Growth? An Empirical Study
}

\author{
Xionglin ZHANG \\ College of Economics \& Management, China Three Gorges University, Yichang 443002, China \\ E-mail: zhangxionglin88@163.com \\ Wenjuan LÜ \\ College of Economics \& Management, China Three Gorges University, Yichang 443002, China \\ E-mail: lwj.se.03@163.com \\ Feng LIN \\ College of Economics \& Management, China Three Gorges University, Yichang 443002, China \\ E-mail: linfenglost@sina.com
}

\begin{abstract}
Scientific and technological talent has become one of the key elements to accelerate economic development all over the world. The internal mechanism of the promoting of economic growth by scientific and technological talent gathering has been analyzed using mathematical modeling methods based on two regional cases. Further the conclusion has been extended to multi-location application. The scientific and technological talent gathering index has been introduced in the application. The data used was accessed from China Population Statistics Yearbook, Science and Technology of China Statistical Yearbook and China Statistical Yearbook. The regional concentration index of scientific and technological talent in different regions has been calculated based on the data. Findings of the research affirmed the positive correlation between scientific and technological talent gathering and regional economic growth. Finally recommendations to promote regional scientific and technological talent aggregation have been proposed.
\end{abstract}

Keywords scientific and technological talent aggregation; regional economic growth; regional concentration index

\section{Introduction}

Scientific and technological talent is the most valuable human capital with outstanding contribution in many aspects. Human resource in China represents power. Scientific and technological talent has critical influences on promoting economic development, enhancing domestic independent innovation capabilities and improving comprehensive national strength of China. Scientific and technological talent gathering is the most advanced and important element agglomeration. It's the dimensional shifting of the human capital. The agglomeration is prerequisite for the optimization of human resource allocation. Scientific and technological talent gathering produces an assemble effect beyond the separate values it can realize. It

Received December 4, 2013, accepted May 21, 2014

Supported by the National Social Science Fund of China (14BJL087) 
gives the agglomeration site a "first mover" advantage to develop sustained economic growth as vanguards which will in turn accelerate the concentration of local talent and promote the local economic development. Therefore, all regions are vigorously promoting their scientific and technological talent aggregation projects with the expectation of occupying the commanding heights of the scientific and technological talent gathering.

Experiences from the world's developed economies have shown that the gathering of scientific and technological talent is an inevitable product of a country's (or region) economic development in a certain developing stage and in turn it will further promote the development of the regional economy. Therefore, the significance of the scientific and technological talent gathering needs to be analyzed from the angle of Chinese social and economic development. It can help accelerating the agglomeration effect of scientific and technological talent to achieve the technological capability development and economic and social development of China.

Scientific and technological talent agglomeration phenomenon has been studied at first to explore the inner laws of the promotion of local economies through scientific and technological talent gathering. Firstly, a simple research of scientific and technological talent gathering in local system has been conducted. Secondly, the research has been expanded to the multiregional scientific and technological talent gathering combined with mathematical models to draw the conclusions. Finally, the conclusions have been empirically tested.

Few researches have been conducted on correlation of scientific and technological talent gathering and Chinese economic growth up till now. With the gathering of scientific and technological talent in China continuously expanding, its impact on the social economy is also gradually deepening. In this case, we studied the basic rules and the general pattern of China's economic development which have great theoretical and practical significance.

\section{Literature Review}

Although the gathering of scientific and technological talent and related issues on the scientific and technological talent gathering's promotion of economic development have been gradually drawing attention in academic research, the studies in this area are mostly in exploratory stage. Few results and related papers have been published. The results of accessing to the research literature relevant to the scientific and technological talent gathering are not satisfactory. Foreign scholars have conducted some in-depth research in this field. For example, Quah ${ }^{[1]}$ examined the economic growth from the perspective of scientific and technological knowledge. Venables $^{[2]}$ discussed the international inequality in IT industry. Marshall ${ }^{[3]}$ proposed that the concentration of talent, industrial agglomeration and urbanization are closely linked, and only be closely combined with industrial clustering could the talent gathering produce the effect. After Marshall, there have been significant developments on theories of industrial clustering. There are many branches. The most influential studies are Weber's location agglomeration theory, Schumpeter's creative industries cluster theory, Hoover's industrial agglomeration scale theory and Porter's enterprise competitive advantage and Diamond Model.

According to the category of talent agglomeration, Krugman ${ }^{[4]}$ and Fritsch and Mueller ${ }^{[5]}$ divided talent agglomeration into transverse talent agglomeration which has been developed in the same type and longitudinal talent agglomeration which has been developed between 
different types of talent agglomeration. Pavitt ${ }^{[6]}$ suggested that in the economic development, the development of novel high-tech industry will greatly enhance the influence of concentration of talent. The interaction between human resources department and trading activities will form the longitudinal talent agglomeration mode. Pérez, Sánchez, de Luis Carnicer ${ }^{[7]}$ and Watts, Porter ${ }^{[8]}$ argued that the development of talent agglomeration have been greatly strengthened the interaction among different units in the social system. The level of the interaction has been a major indicator to the study of various economic links. As a result, the concentration of talent could not only promote economic development, but also reduce the social costs. Many researches have been argued that the concentration of talent not only could promote the emergence and development of a new industry, but also enhance the ability of entrepreneurs to create a favorable environment. These factors played a role once they were formed and would further promote the development of talent agglomeration. Porter ${ }^{[9]}$ holds the point that the country's competitive advantage depends on advanced production factors and professional production factors owned by the country. The two types of production factors determine the quality and development prospects of the competitive advantage. In other words, professionals have an irreplaceable role in national development. Mumford ${ }^{[10]}$ and Todaro ${ }^{[11]}$ studied the relationship between the concentration of talent and urbanization. The findings showed that the only reason for the talent gathering to the city is for higher treatment. The higher a city's treatment level is, the greater the talent migration scale to the urban would be. Brouwer ${ }^{[12]}$ found that companies located in the gathering area often had a larger number of innovative outputs than companies located in remote areas. Audretsch and Feldman ${ }^{[13]}$ tried to measure the importance of the universities' R\&D investment in local innovative production. Their cross-regional studies have shown that the geographic concentration of innovative output was positively correlated to the industrial innovation (by controlling the spatial aggregation of output). The result suggested the spatial aggregation tendency of innovation activities.

Another focus of the study is the scientific and technological talent gathering's contributions to knowledge innovation and economic development. The agglomeration effect of the scientific and technological talent is mainly reflected on: Technological complementarities, interest relevance or for a target (for example, knowledge innovation), technological innovation, knowledge sharing, and so on. The gathering can help improving the utilization of talent, promoting the economy and reducing knowledge sharing costs. It results in positive externalities where the innovation is enhanced and the regional economy is promoted.

\section{Theoretical Model}

We assume there are two kinds of workers (technological and non-technological) in a two-area economy system. The innovation sector needs only technological workers to produce patents, which is necessary for semi-finished production. The innovation sector activities lead to the different types of goods increasing. Another assumption is that the productivity of skilled workers is influenced by the knowledge capital stock, while the stock of knowledge capital is in turn determined by the interaction among skilled workers. The stock of knowledge capital increases along with the amount of workers living in the same area, while the productivity of skilled workers grows along with the knowledge capital stock. Hence the productivity of skilled 
workers increases with their amount. Based on the assumption, we argue that skilled workers tend to gather in one place. In this context, the paper focused on studying the influence of innovation sector and skilled workers gathering on economic growth.

The model established includes two regions $(A$ and $B)$ in economic system. Innovation sectors only use technological labor to produce patents, and these patents are necessary to products. We also assume that a patent is used to produce one kind of products only, i.e. the number of products' types equals to the number of patents. Only in the economic system the total number of skilled workers is unchanged, and we require 1 without loss of generality. Though the total number of skilled workers is unchanged, the growth of intellectual capital will continually promote economic growth. The skilled workers move over time. If we assume share of skilled workers in one region is $\lambda$, the other is $1-\lambda$.

In Formula (1), $b$ represents the number of technological workers needed to produce a patent; $\lambda_{A}$ is the number of skilled workers in area $A$; and $\mathrm{K}_{A}$ is existing knowledge stock in area $A$. According to the research of Fujita and Thisse, the number of patent production per unit time in region $A$ is

$$
\dot{n}_{A}=\frac{\mathrm{K}_{A}}{b} \lambda_{A}
$$

Since knowledge has positive externality, it is influenced by the knowledge stock in various regions. In Formula (2), complementary knowledge share related to knowledge innovation among skilled workers is given as $\psi(0<\psi<1)$, and the knowledge spillovers index between the two regions is given as $\eta(0 \leq \eta \leq 1)$. All knowledge of the technological worker $j$ is given as $h_{j}$, so the available knowledge in area $A$ is

$$
K_{A}=\left[\int_{0}^{\lambda_{A}} h_{j}^{\psi} \mathrm{d} j+\eta \int_{0}^{\lambda_{B}} h_{j}^{\psi} \mathrm{d} j\right]^{\frac{1}{\psi}}
$$

We assume that the knowledge of technological worker $j$ is in proportion to the number of patents in existing knowledge system, that is $h_{j}=\alpha N$. For simplicity, we let $h_{j}=N$. Based on this assumption, we rewrite Formula (2) as

$$
\mathrm{K}_{A}=N\left[\lambda_{A}+\eta \lambda_{B}\right]^{\frac{1}{\psi}}
$$

Taking Formula (3) into (1) is

$$
\dot{n}_{A}=\frac{N}{b}\left[\lambda_{A}+\eta \lambda_{B}\right]^{\frac{1}{\psi}} \lambda_{A}
$$

To simplify the notation, we define $k_{A}=\left[\lambda_{A}+\eta \lambda_{B}\right]^{\frac{1}{\psi}}$. The influence of patents is infinite; hence the company which produces differentiated products is always competitively monopolistic. We assume $\lambda_{A} \equiv \lambda$, and $\lambda_{B} \equiv 1-\lambda$. In entire economic system, the number of patented production within unit time is

$$
\dot{N}=\dot{n}_{A}+\dot{n}_{B}=\frac{N}{b}\left[\lambda k_{A}(\lambda)+(1-\lambda) k_{B}(\lambda)\right]
$$

Let $f(\lambda)=\lambda k_{A}(\lambda)+(1-\lambda) k_{B}(\lambda)$ and make use of $f(\lambda)$, we can rewrite Formula (4) as $\dot{N}=\frac{f(\lambda)}{b} N$. Therefore, when the proportion of skilled workers is $\lambda(0<\lambda<1)$, the growth rate 
of patent categories is

$$
g(\lambda)=\frac{\dot{N}}{N}=\frac{f(\lambda)}{b}
$$

Thus, the patent growth rate is the function of the skilled workers' spatial distribution $\lambda$, and symmetrical about $\lambda=\frac{1}{2}$, and $g(0)=g(1)=\frac{1}{b}$. Binding (4) and (5) we can draw the following conclusions:

For $\eta=0, K_{A}=N \lambda_{A}^{\frac{1}{\psi}}$, no knowledge spillovers, knowledge is only local private goods;

For $\eta=1, g(\lambda)=\frac{1}{b}$, knowledge spillovers is not affected by the distance, and it is the pure public goods, and it can achieve the maximum growth rate;

For $0<\eta<1$, due to $0<\lambda<1$, when $\lambda>1 / 2, g^{\prime}(\lambda)>0, g^{\prime \prime}(\lambda)>0$; when $\lambda=1 / 2$, $g^{\prime}(\lambda)=0, g^{\prime \prime}(\lambda)>0$; when $\lambda<1 / 2, g^{\prime}(\lambda)<0, g^{\prime \prime}(\lambda)>0$.

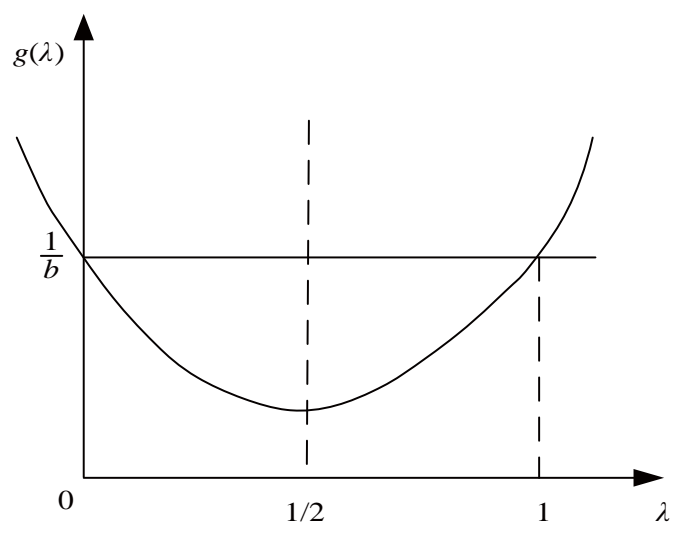

Figure 1 Curve of $g(\lambda)$

It shows that innovative sectors are clustered within a region which means $\lambda$ approaches to 0 or 1 . When $\eta<1$, the number of patents will increase in the fastest speed. For $\lambda=1 / 2$ which means the innovation departments been dispersed in the two regions uniformly, the growth rate of the number of patents is the lowest; when $\eta=1$ and $g(\lambda)=\frac{1}{b}$ reaches the maximum, technique workers (namely knowledge) completely gathered in a department, and local economic growth rate reaches the maximum; when $\lambda=0$ which means technique workers completely gathered in area $B$, and area $B$ achieves the maximum economic growth; when $\lambda=1$ which means technique workers completely gathered in area $A$, and area $A$ achieves the maximum economic growth.

For multi-zone economic system, due to the inconsistent of population size and the number of scientific and technological talent in different region, we introduce scientific and technological talent location agglomeration index, i.e. the quantitative proportion of scientific and technological talent in one region with proportion to the quantitative proportion of the system technological talent. If $\beta<1$ in one region, the degree of aggregation of the scientific and technological talent is less than the level of the entire system in this region; $\beta=1$, the degree of aggregation of the scientific and technological talent is equal to the level of the entire system in this region; $\beta>1$, the degree of aggregation of the scientific and technological talent is more than the level of the entire system in this region. 
For the aforementioned two systems, when $\lambda=1 / 2, \beta=1$ can be achieved correspondingly, i.e. scientific and technological talent uniformly dispersed in area $A$ and area $B$, and the growth rate of the number of patents and economic growth is the lowest; when $1 / 2<\lambda<1$ in area $A$ (or area $B$ ), $\beta>1$ can be achieved in area $A$ (or area $B$ ), and the growth rate of the number of patents and economic growth is higher; when the scientific and technological talent is all concentrated in area $A$ (or area $B$ ), and $\lambda=1$ in area $A$ (or area $B$ ), $\beta<1$ can be achieved in area $A$ (or area $B$ ) correspondingly, and the growth rate of the number of patents and economic growth is the highest.

For multi-zone economy system, when $\beta<1$ in the region, the regional scientific and technological talent gathering degree is low, the growth rate of the number of patents and economic growth is low; when $\beta=1$ in the region, the regional scientific and technological talent gathering degree and the growth rate of the number of patents and economic growth are equal to the average; when $\beta>1$ in the region, the regional scientific and technological talent gathering degree and the growth rate of the number of patents and economic growth are high.

\section{Empirical Study}

\subsection{Calculation of $\beta$}

We construct an $\beta$ index called the scientific and technological talent location index expressed as

$$
\beta_{i j}=\frac{q_{i j} / q_{j}}{q_{i} / q}
$$

It is the ratio of the regional scientific and technological talent to the region's population to the ratio of the national scientific and technological talent to the country's population. It can be used to measure the difference between the technological level of regions and the average level of national science and technology in general, where $q_{i j}$ represents the population of technology industry $i$ in area $j, q_{j}=\sum_{i=1}^{n} q_{i j}$ is the entire population of area $j, q_{i}=\sum_{j=1}^{n} q_{i j}$ is the number of national science and technology talent in industry $i, q=\sum_{j} \sum_{i} q_{i j}$ is the country's total population.

\subsection{Analysis of Technological Talent}

By calculating the average of the scientific and technological talent location gathering index (namely the average of $\beta$ ) in various regions of China from 2000 to 2012, combined with the data of the average per capita GDP in 2000-2012, we count up the average value of $\beta$ and the average per capita GDP and sort the results in ascending order of the average value of $\beta$, i.e. we can sort per capita GDP in ascending order of the average value of $\beta$ (Figure 2).

With the increase of regional the scientific and technological talent gathering index $\beta$, the average per capita GDP also shows an upward trend. We can roughly conclude that the agglomeration index value $\beta$ of regional scientific and technological talent and per capita GDP are positively correlated. Figure 3 is a diagram to present regional per capita GDP and regional scientific and technological talent gathering index value $\beta$. Beijing gathers a lot of researchers, yet lots of manufacturing businesses been moving out, so its relationship point is special which has been rejected. 


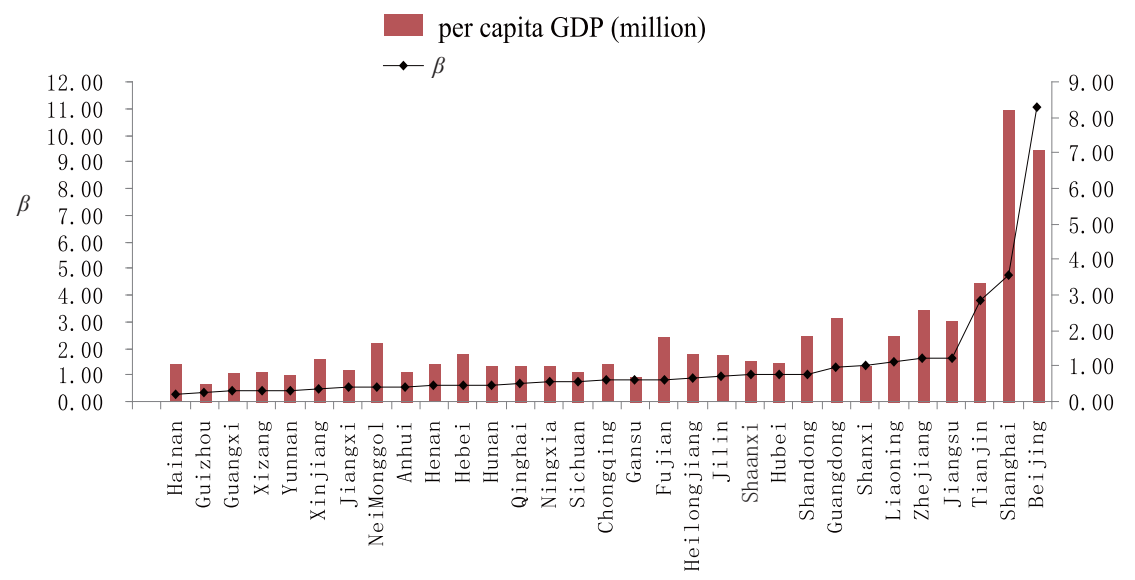

Figure 2 Trend chart of per capita GDP in ascending order of the average value of $\beta$

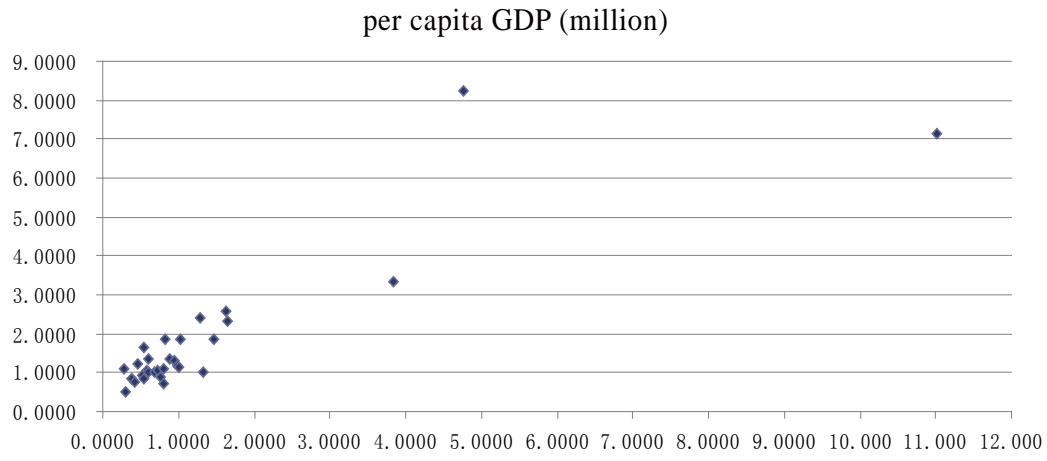

Figure 3 Relationship of regional per capita GDP and $\beta$

Figure 3 can be intuitive about per capita GDP been increasing with the increase of the value $\beta$. Further we make a specific model using "Eviews software" to estimate the value of $\beta$ and per capita GDP of each region. Results are as follows (Table 1).

It shows $Y=0.64 X+0.8$, where $X$ represents the regional scientific and technological talent gathering index $\beta, Y$ represents per capita GDP. It confirmed our inference that per capita GDP and the regional scientific and technological talent gathering index value of $\beta$ have

Table 1 Estimation results of OLS

\begin{tabular}{lllll}
\hline Variable & Coefficient & Std. Error & t-Statistic & Prob. \\
\hline$C$ & 0.800640 & 0.131609 & 6.083456 & 0.0000 \\
$X$ & 0.641551 & 0.075176 & 8.533935 & 0.0000 \\
\hline$R$-squared & 0.715206 & Mean dependent var & 1.549759 \\
Adjusted $R$-squared & 0.705386 & S.D. dependent var & 1.005864 \\
S.E. of regression & 0.545967 & Akaike info criterion & 1.689824 \\
Sum squared resid & 8.644314 & Schwarz criterion & 1.782339 \\
Log likelihood & -24.19227 & F-statistic & 72.82805 \\
Durbin-Wasteon stat & 1.929082 & Prob(F-statistic) & 0.000000 \\
\hline
\end{tabular}


positive correlation, and per capita GDP increases with the value of gathering scientific and technological talent index. Where $R^{2}=0.7152$ which means $71.52 \%$ of the change in GDP per capita is from the changes of regional scientific and technological talent agglomeration index value. In other words, the gathering of the regional scientific and technological talent can promote the growth of the local economy.

\section{Conclusion}

To sum up, the growth of the regional economy and regional scientific and technological talent agglomeration index is positively correlated. In advanced areas in China scientific and technological talent agglomeration has been made a prominent progress. When the gathering of scientific and technological talent happens, it brings along the accumulation of knowledge and the promotion of economic growth. However, degree of scientific and technological talent aggregation in some less advanced areas are still low. Scientific and technological talent gathering do have significant influence on regional economy development. Hence, the incentives to promote scientific and technological talent gathering in backward areas should be enhanced. The recommendations are as follows: 1) Improving policies on scientific and technological talent and providing supporting policies for the flow, introduction and use of scientific and technological talent; 2) Constantly improving the motivating and training policies of scientific and technological talent to reduce the decrease of scientific and technological talent; 3) strengthening scientific and technological infrastructure construction and building comfortable environment for scientific researches; 4) Creating nurturing environment for the development of scientific and technological talent. Through these measures to promote regional scientific and technological talent gathering, the rapid economic development is aimed to be achieved. So that China can get rid of the ranking of developing countries and become a developed country with economic prosperity.

\section{References}

[1] Quah D. Technology dissemination and economic growth: Some lessons for the new economy. London School of Economics and CEPR Working Paper, 2001.

[2] Venables A J. Trade, location and development: An overview of theory. London School of Economics and CEPR Working Paper, 2001.

[3] Marshall A. Principles of economics. London: Macmillan and Co., Ltd., 1890.

[4] Krugman P. Response to Nelson and Schwartz. Journal of Monetary Economics, 2008, 55(4): 857-860.

[5] Fritsch M, Mueller P. The effects of new firm formation on regional development over time. Regional Studies, 2004(38): 961-975.

[6] Pavitt K. Research and development in organizations. International Encyclopedia of the Social \& Behavioral Sciences, 2001: 13220-13224.

[7] Pérez M P, Sánchez A M, de Luis Carnicer M P. Benefits and barriers of telework: Perception differences of human resources managers according to company's operations strategy. Technovation, 2002, 22(12): $775-783$.

[8] Watts R J, Porter A L. R\&D cluster quality measures and technology maturity. Original Research Article Technological Forecasting and Social Change, 2003, 70(8): 735-758.

[9] Porter M E. The competitive advantage of nations. Business Week, 1990.

[10] Mumford L. The city in history: Its origins, its transformations, and its prospects. Harcourt, Brace \& World, Inc, 1961. 
[11] Todaro M P. A model of labor migration and urban unemployment in less developed countries. America Economic Review, 1969, 59(1): 138-148.

[12] Brouwer A. Immigrants need not apply. Ottawa: Caledon Institute of Social Policy, 1999.

[13] Audretsch D B, Feldman M P. R\&D spillovers and the geography of innovation and production. America Economic Review, 1996, 86(3): 630-640.

\section{Appendix}

Table 2 Per capita GDP in ascending order of the average value of $\beta$

\begin{tabular}{|c|c|c|c|}
\hline area & the average value of $\beta$ & the average value of per capita GDP(million) & rank \\
\hline Hainan & 0.274571 & 1.083653 & 1 \\
\hline Guizhou & 0.307247 & 0.515979 & 2 \\
\hline Guangxi & 0.386177 & 0.824176 & 3 \\
\hline Xizang & 0.389369 & 0.858759 & 4 \\
\hline Yunnan & 0.420579 & 0.767076 & 5 \\
\hline Xinjiang & 0.471091 & 1.231662 & 6 \\
\hline Jiangxi & 0.521002 & 0.913070 & 7 \\
\hline Inner Mongolia & 0.548985 & 1.652872 & 8 \\
\hline Anhui & 0.552286 & 0.843703 & 9 \\
\hline Henan & 0.581752 & 1.055381 & 10 \\
\hline Hebei & 0.597019 & 1.370926 & 11 \\
\hline Hunan & 0.608970 & 1.010937 & 12 \\
\hline Qinghai & 0.686312 & 1.008121 & 13 \\
\hline Ningxia & 0.718484 & 1.040436 & 14 \\
\hline Sichuan & 0.759632 & 0.870887 & 15 \\
\hline Chongqing & 0.796070 & 1.089848 & 16 \\
\hline Gansu & 0.801533 & 0.716618 & 17 \\
\hline Fujian & 0.832535 & 1.842921 & 18 \\
\hline Heilongjiang & 0.891547 & 1.370301 & 19 \\
\hline Jilin & 0.952409 & 1.323914 & 20 \\
\hline Shanxi & 0.990358 & 1.174581 & 21 \\
\hline Hubei & 1.003123 & 1.135832 & 22 \\
\hline Shandong & 1.024686 & 1.870913 & 23 \\
\hline Guangdong & 1.284277 & 2.391336 & 24 \\
\hline Shaanxi & 1.328319 & 1.028122 & 25 \\
\hline Liaoning & 1.466954 & 1.868594 & 26 \\
\hline Zhejiang & 1.625312 & 2.570383 & 27 \\
\hline Jiangsu & 1.654282 & 2.308475 & 28 \\
\hline Tianjin & 2.829983 & 3.335284 & 29 \\
\hline Shanghai & 3.766426 & 4.843551 & 30 \\
\hline Beijing & 7.126442 & 4.124206 & 31 \\
\hline
\end{tabular}

Note: Data derived from the China Statistical Yearbook. 